\title{
BMJ Open Exploring pathways to mental healthcare for urban Aboriginal young people: a qualitative interview study
}

\author{
Deanna Kalucy, ${ }^{1}$ Janice Nixon, ${ }^{1}$ Michael Parvizian, ${ }^{\circ} 2$ Peter Fernando, ${ }^{1}$ \\ Simone Sherriff, ${ }^{1,3}$ Jennifer McMellon, ${ }^{4}$ Catherine D'Este, ${ }^{5}$ Sandra J Eades, ${ }^{6}$ \\ Anna Williamson ${ }^{1,7}$
}

To cite: Kalucy D, Nixon J, Parvizian M, et al. Exploring pathways to mental healthcare for urban Aboriginal young people: a qualitative interview study. BMJ Open 2019;9:e025670. doi:10.1136/ bmjopen-2018-025670

- Prepublication history and additional material for this paper are available online. To view these files, please visit the journal online (http://dx.doi. org/10.1136/bmjopen-2018025670).

Received 26 July 2018

Revised 28 June 2019

Accepted 28 June 2019

A) Check for updates

(C) Author(s) (or their employer(s)) 2019. Re-use permitted under CC BY-NC. No commercial re-use. See rights and permissions. Published by BMJ.

For numbered affiliations see end of article.

Correspondence to Dr Anna Williamson; anna.williamson@saxinstitute. org.au

\section{ABSTRACT}

Objectives To explore the perceptions of Aboriginal Community Controlled Health Service (ACCHS) staff involved in providing mental healthcare to Aboriginal young people of the current and ideal pathways to mental healthcare for urban Aboriginal young people attending ACCHSs, and to identify what additional supports staff may need to provide optimal mental healthcare to Aboriginal young people.

Design Qualitative interview study conducted during May 2016-2017.

Setting Primary care, at two ACCHSs participating in the Study of Environment on Aboriginal Resilience and Child Health in New South Wales.

Participants Purposive sampling of staff involved in mental healthcare pathways of Aboriginal young people, including general practitioners (GPS), nurses and Aboriginal Health Workers (AHWs).

Results All individuals approached for interview $(n=21)$ participated in the study. Four overarching themes and seven sub-themes were identified: availability and use of tools in practice (valuing training and desire for tools and established pathways), targeting the ideal care pathway (initiating care and guiding young people through care), influencing the care pathway (adversities affecting access to care and adapting the care pathway) and assessing future need (appraising service availability).

Conclusions Participants desired screening tools, flexible guidelines and training for healthcare providers to support pathways to mental healthcare for Aboriginal young people. Both GPs and AHWs were considered key in identifying children at risk and putting young people onto a pathway to receive appropriate mental healthcare. AHWs were deemed important in keeping young people on the care pathway, and participants felt care pathways could be improved with the addition of dedicated child and adolescent AHWs. The ACCHSs were highlighted as essential to providing culturally appropriate care for Aboriginal young people experiencing mental health problems, and funding for mental health specialists to be based at the ACCHSs was considered a priority.

\section{INTRODUCTION}

Mental health problems are a significant health issue affecting young Australians. ${ }^{1-3}$ While most Aboriginal young people are

\section{Strengths and limitations of this study}

- This is the first study to interview mental health service providers working with Aboriginal young people to explore their perceptions of what the current and ideal mental healthcare pathways are for Aboriginal young people and identify opportunities for improvement.

- Our findings are based on staff perspectives from only two urban Aboriginal Community Controlled Health Services (ACCHSs), and while they appear to accord with the broader literature, they may not be generalisable.

- The views of consumers are not captured in the current paper, this will be an important focus of future work.

- The qualitative data reported in this paper will be complemented by a forthcoming detailed examination of the services available within and around the ACCHSs.

- This qualitative study is part of the broader Study of Environment on Aboriginal Resilience and Child Health (SEARCH) programme that seeks to ensure that the data collected from the SEARCH cohort study is built on and used to bring about change for Aboriginal communities.

doing well in terms of mental health, current information suggests that Aboriginal young people experience higher levels of mental health problems than the general population of young people in Australia. ${ }^{4-7}$ Two large studies of Aboriginal children aged 4-17 years found that $24 \%-28 \%$ were at high risk of clinically significant emotional or behavioural difficulties ${ }^{4}{ }^{5}$; this compares to $10 \%$ in a national data study of Australian children aged $4-17,{ }^{7}$ and $7 \%$ of children aged $4-15$ in New South Wales (NSW) ${ }^{6}$ All four studies looked at overall mental health, using Goodman's Strengths and Difficulties questionnaire (SDQ) tool. ${ }^{89}$ The high levels of mental health problems experienced by Aboriginal young people are linked to elevated levels 
of stressful life events, ${ }^{10} 11$ the experience of racism ${ }^{12} 13$ and the ongoing grief, loss and disadvantage that are a legacy of colonisation. ${ }^{14}$ There is increasing recognition of the flow-on effects of poor mental health with evidence suggesting that young people who experience mental illness are less likely to finish school or university ${ }^{15}$ and are more likely to be unemployed later in life. ${ }^{16}$ Moreover, it has been estimated that $90 \%$ of Aboriginal young people in the juvenile justice system in NSW have a psychological disorder. ${ }^{17}$

Half of all lifetime cases of mental health disorders start by 14 years of age,$^{18}$ and mental health problems often continue from childhood or adolescence to young adulthood. ${ }^{19-21}$ A variety of types of mental healthcare (from family interventions that reduce risk factors to psychosocial treatment to medication) have been shown to be effective in treating mental health disorders among young people. ${ }^{22-26}$ Unfortunately, however, many young people experiencing challenges do not access mental healthcare. Australian parent-reported data suggest that only 56\% of children with a mental health diagnosis had accessed services in the last 12 months. ${ }^{7}$ Currently, robust data on Aboriginal child and adolescent mental health service use at the primary care and specialist level do not exist. A qualitative study conducted in 2010 sought the views of Aboriginal parents/caregivers and health workers on their experiences accessing and providing mental healthcare to Aboriginal young people, respectively. This study reported a severe shortage of mental health services available for Aboriginal young people. ${ }^{27}$ Barriers to accessing services were also revealed, including fears of government authorities removing children and a lack of intersectoral collaboration to support effective prevention and treatment. ${ }^{27}$ Another work has reiterated that significant barriers for Aboriginal Australians in accessing mental health services exist related to local availability and issues of cultural appropriateness. ${ }^{28}$

The last 5 years has seen an increase in funding for mental health services and programmes for Aboriginal people. ${ }^{29}$ However, recent data show Aboriginal young people being hospitalised for mental health events at a significantly higher rate than the general population, ${ }^{30}$ and rates of suicide among young Aboriginal people remain high. ${ }^{31}$ While there are systematic reviews of Indigenous mental health programmes available internationally, ${ }^{32}$ in the Australian context, the small amount of published work that exists has largely been descriptive. ${ }^{33}$ Only a few programmes and services have been evaluated, meaning a better understanding of 'what works' is required. ${ }^{34}$ It is essential that mental healthcare services for Aboriginal young people be both available and accessible, including ensuring services are safe and culturally appropriate. ${ }^{2}$ As the first point of call for many families in Australia, general practitioners (GPs) at the primary care level have an important role to play in the recognition and management of mental health concerns in young people. ${ }^{1}$ However, it is known that GPs can experience difficulties identifying mental health concerns in young people, particularly when they are less severe. ${ }^{35}$ A significant proportion of Australian Aboriginal people obtain primary healthcare from an Aboriginal Community Controlled Health Service (ACCHS). ${ }^{36}$ ACCHS-based GPs as well as Aboriginal Health Workers (AHWs) and nurses, therefore, have a crucial role to play in initiating and facilitating mental healthcare provision to Aboriginal young people. ${ }^{28}{ }^{37}$ However, the extent to which these providers feel equipped and supported to fulfil these roles is unknown. ${ }^{27}$

To address the availability and accessibility of services, it is important to comprehend how Aboriginal young people enter and transition through care. Goldberg and Huxleys' model of pathways to care provides a basis for understanding the movement of patients into and through the mental healthcare system. Adapted for use in this study, Goldberg and Huxley propose that the system is made up of five levels (from community to the hospital), with filters between each level-these filters are the points at which the patient transitions (or may not transition) to the next level of care. ${ }^{38}$ Filters for each patient are affected by factors such as accessibility, patient values, diagnoses and decisions to refer. ${ }^{38}$ It is suitable for use in the NSW child and adolescent mental healthcare context (where this study is set), which consists of a three-level framework: level 1-primary care; level 2-secondary level (specialist care with the initial referral coming from a primary care professional) and level 3-tertiary level, highly specialised care including inpatient services. ${ }^{40}$ Preceding primary care is the community level, where there is opportunity for recognition of mental health concerns by parents, other family members, friends and school personnel, and also the potential to provide support along the care pathway. A recent review was unable to identify any mental healthcare pathways that had been developed for Aboriginal young people, modified or even tested for suitability for Aboriginal young people. ${ }^{41}$ Moreover, the actual mental healthcare pathways used by Aboriginal young people are currently unknown. ${ }^{41}$ Given the importance of improving the mental health of Aboriginal young people, a better understanding of how frontline ACCHS staff currently initiate and navigate Aboriginal young people through mental healthcare pathways, and what could be done to improve the pathways is required. Through qualitative interviews with ACCHS GPs, AHWs and other ACCHS staff involved in providing mental healthcare, this study aims to explore ACCHS staff perceptions on what the current and ideal pathways to mental healthcare are for Aboriginal young people, and what additional supports ACCHS staff may need to provide optimal mental healthcare to Aboriginal young people.

\section{METHODS}

Setting

This work was conducted under the Study of Environment on Aboriginal Resilience and Child Health (SEARCH) programme umbrella. ${ }^{42}$ Developed to provide much 
needed health research evidence to address the priorities of urban Aboriginal communities, the SEARCH programme is based on a partnership between a multidisciplinary team of researchers, the Aboriginal Health and Medical Research Council NSW and four ACCHSs, located in urban and large regional centres in NSW. ${ }^{43}$ ACCHSs are primary healthcare services that are owned, managed and predominately staffed by local Aboriginal community members. They provide holistic, comprehensive and culturally appropriate healthcare that addresses the physical, social, emotional and cultural well-being of the individual and their community. ${ }^{44}$ With Aboriginal culture at the forefront of these organisations, they play a unique role in providing healthcare to Aboriginal people. Recent data show improved clinical and health outcomes in many areas for Aboriginal clients of ACCHSs in Australia. ${ }^{36}$ The centrepiece of the programme is the SEARCH cohort study, which is the largest cohort study of urban Aboriginal children in Australia. ${ }^{45}$ The current qualitative study on mental healthcare pathways was initiated in response to findings from the SEARCH cohort study which showed high rates of Aboriginal young people at risk for emotional and behaviour problems, ${ }^{4}$ data linkage work which illustrated high rates of mental health-related hospitalisation for Aboriginal young people for mental health problems ${ }^{30}$ and qualitative data highlighting community concerns around mental health. ${ }^{27}$ As most research published thus far has examined general Aboriginal child and adolescent mental health, for this paper, mental health problems will be defined broadly as behavioural or emotional problems or associated impairment. The term 'young people' and 'children and adolescents' will be used interchangably, referring to all individuals aged $0-17$ years, inclusive.

\section{Sampling and study participants}

Participants were recruited from two ACCHSs (1=urban location; 2=large regional area) in NSW participating in SEARCH. Purposive sampling was used to discern the perspectives of a variety of ACCHS staff (both Aboriginal and non-Aboriginal) including GPs, nurses and AHWs. AHWs work closely with GPs, nurses and other health providers to deliver and support healthcare, playing important cultural advisory roles and facilitating communication between Aboriginal and non-Aboriginal healthcare providers and organisations to overcome cultural barriers. ${ }^{46}$ Participants were selected if they were involved in the mental healthcare pathways of children or adolescents (aged 0-17 years), and were identified as having relevant expertise by experienced local ACCHS staff members with intimate knowledge of the services at each of the ACCHSs. Participants invited for interview had to have been working at the ACCHS in a role related to child and adolescent mental health for at least 1 month. We sought a balance of new and experienced staff, and younger and older staff members. Participants were invited to take part in the study via email and/or phone. All individuals approached for interview $(n=21)$ consented to participate in the study. Of the 21 participants recruited, 12 had worked at the ACCHS for $>5$ years and 9 had been employed for $\leq 5$ years, with staff aged between 24 and 65 years.

\section{Patient and public involvement}

Patients and the public were not involved in this research.

\section{Data collection}

An interviewer (DK-SEARCH Senior Research Officer, the Sax Institute) in partnership with an Aboriginal researcher (JN-SEARCH Project Coordinator, the Sax Institute) conducted semistructured interviews during May 2016-2017 using predefined interview guides (online supplementary file 1). Both interviewers were female, trained in qualitative research methods and experienced in conducting qualitative interviews with ACCHS staff. The participants were aware of the SEARCH programme as the study has run in their ACCHSs for $>10$ years. Participation was voluntary, and all participants provided written, informed consent. Most interviews were conducted individually $(\mathrm{n}=16)$, however two interviews were conducted in small groups (one with two participants and the other interview with three participants) due to the availability of participants. All interviews were held in a private meeting room at the ACCHS where the participant was employed. The interview guide was pilot tested internally among the research team before interviews commenced, and no repeat interviews were required. Before the interview commenced, the participants were given a brief introduction to the topic area. The interview contained three components: (1) the completion of demographic data and consent forms (self-completed by participants); (2) interview questions (online supplementary file 1); (3) an activity where participants were asked to draw pathways on two diagram templates adapted from the Goldberg and Huxley model ${ }^{38}$ to indicate their perception of the current and ideal mental healthcare pathways, respectively, for Aboriginal young people (online supplementary file 2). This activity included discussions of what might prevent or assist young people from following the ideal treatment pathway.

Data collection ceased when data saturation was reached, where additional interviews were giving more examples to support existing themes, rather than being the basis for any new ones. ${ }^{47}$ No additional notes were taken during the interview process. Interviews were audiotaped and transcribed by an individual without connection to the communities. Soft copies of transcripts were saved in a deidentified format in password-protected files at the Sax Institute. Audiotapes were securely transported and stored within locked filing cabinets at the Sax Institute.

\section{Data analysis}

Principles of grounded theory were used as the basis for the coding and analysis of the information from the interviews. ${ }^{48}$ Two researchers (DK (BIntSt (Hons), MA(ScoSc) 
(Res), MPH) and MP (Queen Elizabeth Scholar (BHSc)), both trained in qualitative research methods, independently coded the data to discern themes inductively. ${ }^{49}$ The lead author DK entered all transcripts into HyperRESEARCH (V.3.5.2; Research-ware), a software programme used to manage qualitative data. Researchers examined the training and tools usage data and considered the extent to which the actual pathways differed from the ideal pathways, and whether there was consistency across the actual and ideal pathways reported by different participant types. Participants discussed reasons why the actual pathway might differ from the ideal and how the ideal pathway could be attained, and this information was considered in the context of the completed diagrams. DK and MP then came together with AW and JN to discuss the grouping of codes to create categories which then allowed for the identification of themes. AW and JN played an important role interpreting the codes and categories to identify the themes. Some themes had multiple layers within them and were subsequently broken down into sub-themes. Over six meetings, the group came to a consensus on the themes. A summary of findings and their interview transcript was sent to participants by email to obtain feedback over a 2-week timeframe; two participants responded, with their feedback included in the analysis. The COnsolidated criteria for REporting Qualitative research Checklist and the Standards for Reporting Qualitative Research were used to guide the study design and manuscript preparation.

\section{RESULTS}

\section{Study participants and interviews}

Thirteen GPs/nurses and 8 AHWs/familysupport workers/ACCHS managers were interviewed. Nine participants identified as Aboriginal and 12 did not identify as Aboriginal (table 1). Nineteen participants reported being directly involved in providing mental healthcare to Aboriginal young people. The other two participants had indirect roles as they held management positions supervising mental healthcare provision at their ACCHS. Seven participants were known to the researchers through previous study participation. The average duration of interviews was $26 \mathrm{~min}$ (range: 9-37 min). Transcripts were generated for all 16 interviews that took place, totalling 245 pages of transcript.

Participating ACCHSs varied in size and staff composition and had different levels of access to and relationships with specialists, community health services, mental health programmes, private physicians and hospitals in their local area. At the time of interview, ACCHS 1 had a defined Social and Emotional Wellbeing (SEWB) programme while ACCHS 2 did not. The following four themes arose from the coding and analysis of the data: availability and use of tools in practice, targeting the ideal care pathway, influencing the care pathway and assessing future need. These are described and illustrative quotes are presented in table 2 .
Table 1 Participant characteristics $(n=21)$

\begin{tabular}{lll}
\hline Characteristic & Total (n=21) & Percentage \\
\hline Age, years & & \\
$<40$ & 8 & $(38)$ \\
$40-49$ & 8 & $(38)$ \\
$\geq 50$ & 5 & $(24)$ \\
ACCHS role & & \\
$\quad$ General practitioner/Nurse & 13 & $(62)$ \\
$\begin{array}{l}\text { Aboriginal health worker/Other } \\
\text { (Practice Manager, Programme }\end{array}$ & 8 & $(38)$ \\
Manager, Family Support & & \\
Officer & &
\end{tabular}

Full time versus part time

\begin{tabular}{lrl} 
Full time & 14 & $(67)$ \\
Part time & 7 & $(33)$ \\
Identified as Aboriginal & & \\
$\quad$ Yes & 9 & $(43)$ \\
No & 12 & $(57)$ \\
Years working at ACCHS & & \\
$0-5$ & 9 & $(43)$ \\
$6-10$ & 5 & $(24)$ \\
$11+$ & 7 & $(33)$ \\
Site & & \\
ACCHS 1 & 9 & $(43)$ \\
ACCHS 2 & 12 & $(57)$ \\
\hline
\end{tabular}

ACCHS, Aboriginal Community Controlled Health Service.

\section{Availability and use of tools in practice \\ Valuing training}

Participants drew on a variety of skills and knowledge gained through formal training (eg, university or vocational education) and informal learning (eg, on the job learning) in their work with Aboriginal child and adolescent mental health. Aboriginal participants reported drawing on their knowledge of the community, including shared past experiences and understandings. Most participants had some training in working with Aboriginal young people, or child and adolescent health or mental health. However, many participants had not received any specific training regarding Aboriginal child and adolescent mental health, and regardless of their training were supportive of additional training in this area. There were three types of training that were specifically desired: (1) training on providing culturally appropriate healthcare to Aboriginal young people (particularly for new non-Aboriginal workers), (2) training in identifying and addressing mental health concerns in Aboriginal young people and (3) training to support the implementation of guidelines for working with Aboriginal young people experiencing mental health concerns. 
Table 2 Illustrative quotations

\begin{tabular}{|c|c|}
\hline Theme & Illustrative quotation \\
\hline \multicolumn{2}{|c|}{ Availability and use of tools in practice } \\
\hline \multirow[t]{2}{*}{ Valuing training } & “...l've done a lot of generalist, but not specific to Aboriginal kids, I don't think there's much out there." \\
\hline & $\begin{array}{l}\text { "...when you do courses and that, it's mainly aimed at adults and there's nothing really specific or put in for } \\
\text { adolescents and younger children. So, yeah, I think it's needed big time." }\end{array}$ \\
\hline \multirow[t]{2}{*}{$\begin{array}{l}\text { Desire for tools and } \\
\text { pathways }\end{array}$} & $\begin{array}{l}\text { "Well, it's hard to use things like your K10s [Kessler psychological distress scale, } 10 \text { items] and your DASs } \\
\text { [Depression, Anxiety and Stress Scale] on kids. If there was a guideline for kids, it would be great." }\end{array}$ \\
\hline & $\begin{array}{l}\text { "If there were clinical pathways that led somewhere, they could be useful. But there always needs to be the flexibility } \\
\text { to not follow them directly." }\end{array}$ \\
\hline
\end{tabular}

Targeting the ideal care pathway

Initiating care "This is my personal feeling that all these people from the home, your parent, adolescent, I think if their first contact was with an Aboriginal health worker, I think that they would feel better to do that."

"I think a GP is a good point of contact for parents to raise concerns but I do think that the Aboriginal Health Workers can have a big impact on supporting the GP with regards to communication with the parents and the carers and I think ideally if you can have an Aboriginal Health Worker purely looking after-you know, social wellbeing of kids that would be a really good thing to have, which is something we don't have in this service."

Guiding youth "We're going back to the Aboriginal Health Worker. They play a pivotal role, or youth worker-they play the pivotal through care role between GP and parents and community, school. They're going to be there and they're going to be the ones that are going to answer all the questions in a way that the parents and the community's going to understand and not be bamboozled by all these big words. They need to be included in the care plan. The health worker and your GP, youth worker-they're very important people."

"If they didn't understand what they (the GP/specialist) were talking about l'd do it most times (sit in the appointment with the client). Because they (the client) would get in there and they just won't say anything. They'll just nod their head."

"I am actually am working with an 18 year old at the moment, and her thing is that she wants to go to the appointments but she just doesn't want to get up. So l'll start ringing her, alright, get ready, we'll go and grab some lunch and then we'll go. Oh, I don't really want to go. Come on, you know how good you feel after it. Like-do you know what I mean? So it's just that. Sometimes with kids they don't have that because mum has got three or four other kids needing things too. So yeah, that's hard."

Influencing the care pathway

Adversities affecting "The first thing l'd think of is transport as a barrier. I think of money. If they don't have money to catch a bus they're access to care not going to get here. ... Yeah and that's where everything breaks down there."

"I think it's really hard. I've seen families here that have lots of issues. I can think of one family where there was a lot of stuff going on. I think they've been able to slightly pull through with a lot of support from services, a lot of support, but there's other families - and I think they're lost to the health system that hasn't done the right thing by them."

Adapting the care

"I think if they had that contact with the Aboriginal Health Workers, it's going to be less of a shock to the person, pathway because the Aboriginal Health Workers, they'll go and sit in with the consult or things like that. I've done it many times and my clients have said, oh thank you, because I wouldn't have even gone. The Aboriginal Health Worker is the most valuable tool within the whole organisation, because they're that first step for that person who's in crisis." "I've had a client that was on heroin, ice and marijuana. It took threeyears. Three years you know and it was just that ongoing, you can't shut the door on them. You've got to have-every contact you have with that person, you have to look at them with hope, whether it may be like two years down the track and they're still doing the same thing, that's what adolescents do, they do the same thing whether you like it or not. Yeah, you've just got to keep working at it. Eventually, you'll get there."

"Too often the health system penalises people for going to the wrong entry point for the problem that they turn out to have, and I think that's a problem. People should be able to go to where they feel is appropriate, and be navigated around the system by people who know what they're doing. Their first port of call should be able to do some sort of assessment and say ah, I think the problem is in this area. Come and meet my friends here who are excellent, l'll take you to them. That sort of atmosphere. Again, GPs, health workers, practice nurses are good at doing that, but if someone's presenting to Emergency they'll do that less well, but they ought to be doing that well."

Assessing future need

Appraising service availability

"We need to have some sort of a CAMHS [Child and Adolescent Mental Health Service] team, even if it's one worker, two days a week. We need that person to be able to come in and to be able to talk with the kids in a way that they're going to feel comfortable and want to continue with treatment, or go to therapies. We need it, but it's not available at this point. That's my wish list."

"There's a gap in paediatric mental health. It seems to be-if they're more of the high teenagers and there's headspace* that's not a problem. You can go there. But that younger group, there really is a serious lack of where you can go."

*Headspace centres are a network of enhanced primary care services where young people (12-25 years) with mild to moderate mental health problems can access a broad range of in-house services or be connected to complementary services within the community. 


\section{Desire for tools and established pathways}

Participants consistently noted a lack of guidelines, decision rules and screening tools for working with Aboriginal young people with mental health problems. Some participants used existing adult screening tools (eg, the Kessler 10 (K10) Psychological Distress Scale $)^{50}$ with adolescents. A gap in resources was frequently noted for primary school aged children. At ACCHS 1, GPs reported using the HEADSS (Home, Education and Employment, Activities, Drugs and Alcohol, Sexuality, Suicide risk/depression) assessment conversational tool. ${ }^{51}$ The majority of Aboriginal participants interviewed noted that they used their connection to and knowledge of their local Aboriginal community to assist in the identification of mental health problems. All participants desired additional screening tools and targeted but flexible guidelines which support the identification of concerns and the provision of culturally appropriate care to Aboriginal young people with mental health problems.

\section{Targeting the ideal care pathway Initiating care}

Under current pathways, participants felt the majority of Aboriginal young people are seen by the GP as the usual provider of referrals in the Australian system, although AHWs also initiate care in many instances. Participants were split on who the ideal first point of contact for young people within the ACCHS was: the AHW or the GP. However, all participants viewed AHWs and GPs as key collaborators in initiating an ideal care pathway. Involving the AHW from the outset was seen as vital to improve communication between parents and health professionals and to help overcome the shame and stigma of accessing mental health services that may otherwise prevent families from doing so. Many participants noted that they are 'on the look-out' for mental health problems when they know other problems exist in the child's family environment, such as domestic violence and substance abuse, and that this is a unique role the ACCHS plays in its provision of holistic care to families.

\section{Guiding young people through care}

Participants noted a variety of currently used strategies to guide young people through mental healthcare pathways. Most participants (across all participant types) indicated that having an AHW that the young person was familiar with facilitating and sitting in on GP and specialist appointments (both within and outside of the ACCHS) was critical in supporting communication, building trust and improving cultural safety. Culturally safe care is free from any unintended disempowering of the recipient. ${ }^{52}$ While AHWs were employed at both ACCHS, they were reported to be operating at capacity. To provide optimal care collaboratively with GPs and specialists, it was suggested that an AHW dedicated to young people would be part of an ideal pathway.

Mental health specialist services were considered necessary for Aboriginal young people experiencing mental health problems. Under the current pathways, younger children were normally referred to paediatrician or psychologist, while adolescents were often referred to a psychologist, psychiatrist or an AHW (youth worker or drug and alcohol worker). Staff at ACCHS 1 reported that getting appointments with the specialist in-house was often possible; however, mainstream services were also used frequently. Some staff att ACCHS 2, considered access to specialists internally to be limited, and noted a reliance on mainstream providers. There was a strong preference for specialist services to be available within the ACCHSs in an ideal pathway to care, with many participants noting that many Aboriginal young people do not feel comfortable accessing mainstream services. However, mainstream services were deemed useful in instances where the client had privacy concerns, with some noting that a small number of young people may not feel comfortable attending the ACCHS because they might worry people they know will hear about their business, particularly with respect to mental health where feelings of shame and stigma may exist.

Some participants noted that certain mainstream primary care services could be helpful for young people with mild to moderate problems, while those experiencing more severe difficulties may require hospitalisation (eg, adolescents contemplating suicide). GPs largely saw themselves as coordinators of the child's overall healthcare (including mental health), rather than playing a key role in the treatment of children's mental health problems. Providing continuity of care was highlighted as important for Aboriginal young people experiencing mental health problems.

\section{Influencing the care pathway}

\section{Adversities affecting access to care}

Participants indicated a variety of barriers to Aboriginal young people entering and continuing along a mental healthcare pathway. Key barriers cited to accessing mental healthcare included transport difficulties, feelings of shame, inadequate access to publicly funded specialists, high cost of accessing private services and insufficient supports for young people and their families throughout the process. Missed appointments leading to discharge from some external service providers was another common concern in the current pathway. Participants noted that young people are reliant on parents/ caregivers to take them to appointments, and where other issues are present in the family there are added barriers to obtaining care. Participants noted that communication between mainstream providers and the ACCHS was currently lacking, and in an ideal pathway would like more communication from mainstream services to allow both to provide better care.

\section{Adapting the care pathway}

Given the identified barriers, participants emphasised the importance of flexibility in an ideal care pathway to ensure appropriate care is received, particularly around 
making and attending appointments. Ongoing strategies in the current pathway to counteract these barriers were noted including the provision of support to attend appointments (attending the appointment with the young person and their family), appointment reminder systems and some provision of transport. However, participants reported that more support was needed, both for the caregiver and child throughout the care process. While AHWs currently carry out many of these roles in the ACCHS, due to the high level of need, participants emphasised that a dedicated child and adolescent health or child and adolescent social and emotional well-being AHW would be part of an ideal pathway to help support Aboriginal young people to start and stay on the ideal pathway to mental healthcare.

\section{Assessing future need}

Appraising service availability

Participants indicated that a significant proportion of their work with young people at their ACCHS involved mental health. Despite this, however, some participants believed that these young people could not currently obtain the services they needed. Some reported a lack of specialised mental health services for young people in general at ACCHS 2, both within the ACCHS and in the surrounding area. In contrast, many participants in ACCHS 1 believed that young people at their ACCHS did have the potential to access necessary services; however, they cautioned that continuing resources to overcome barriers to accessing care were required. Across both ACCHSs, a need for AHWs to focus on young people (aged primary school and above) and specialist services to be located in-house were highlighted as a key parts of an ideal care pathway.

\section{DISCUSSION}

As articulated in the themes, participants reported that a large proportion of their work with young people covered mental health issues. There was a desire for additional training, screening tools and flexible guidelines to support the provision of care to Aboriginal young people. The perceived current and ideal pathways generally commenced with either the GP or AHW, but there was much agreement that the ideal pathway would see the GP and AHW collaboratively support care provision to the young person. This could include facilitating access to further care, for example, with a mental health specialist. Participants reported that in current practice, while AHWs were part of the service structure at both sites, they were considered to be 'at capacity'; therefore, this collaborative model of care provision was not readily available for some young people and their families. Thus, a dedicated AHW for young people was considered key in an ideal pathway. In an ideal pathway, the Aboriginal young person would be able to access specialist mental health services within the ACCHS. In the current pathway, participants felt specialist mental healthcare was often available in-house at ACCHS 1; however, in-house specialist care was considered limited at ACCHS 2, and indeed in the surrounding geographical area. The findings presented in the themes are largely consistent with the literature as detailed in the discussion below.

Most participants in our study reported that they were not aware of any screening tools to detect mental health problems among Aboriginal young people and expressed a need for a tool of this nature. Some reported using adult mental health screening tools (eg, the K10), while others used conversational tools (eg, HEADSS) for adolescents. No tool was used consistently. While there are numerous measures for assessing mental health outcomes among young people, only three measures have been shown to be acceptable and valid for use among Aboriginal populations: the $\mathrm{SDQ}^{853-56}$ the Strong Souls assessment tool $^{57}$ and the Westerman Aboriginal Symptoms Checklist (WASC-Y) ${ }^{58}$ While Strong Souls ${ }^{57}$ and the WASC-Y ${ }^{58}$ are both appropriate for Aboriginal adolescents, the SDQ is the only tool appropriate for measuring the mental health of children (aged $<13$ years). ${ }^{853-55}$ In NSW, the SDQ is currently part of the standard assessment protocol used in mainstream mental health services. ${ }^{59}$ This study provides an opportunity to explore the potential use of this tool for ACCHS staff working in Aboriginal child and adolescent mental health.

In line with the findings of a recent review, participants consistently reported that they were not aware of any guidelines available to support mental healthcare pathways for Aboriginal young people experiencing mental health problems. ${ }^{60}$ Staff desire for guidelines (which are flexible and with accompanying training) to direct mental healthcare for Aboriginal young people is echoed by a recent qualitative study, which also showed clear support for the development of pathways to guide early mental health intervention and a need for these to be accompanied by training. ${ }^{61}$ Paediatricians and psychiatrists have also called for the development of integrated and responsive models of care for children and young people with mental health problems. ${ }^{62}$ Other studies outside of Australia have also shown that guidelines and standards could support GPs in the decision-making and referral process for children presenting with mental health problems. ${ }^{63-65}$

Overall, there was considerable agreement on the ideal pathway to mental healthcare. While neither service had a dedicated child and adolescent AHW, many participants saw them as essential in an ideal mental healthcare pathway for Aboriginal young people. Consistent with other studies, communication was considered a major barrier to effective mental healthcare for Aboriginal people. ${ }^{6}$ AHWs, who understand both the ACCHS and mainstream way of providing healthcare, can play a cultural brokerage role and bridge the communication gaps $^{6167}$ and can support a culturally safe environment for Aboriginal patients, the necessity of which is widely acknowledged. $^{68} 69$ AHWs were also seen to be vital in providing support, reminders, transport and facilitating 
care alongside GPs or mental health specialists, where required. Transportation is a noted barrier in accessing healthcare, particularly in lower-income populations, ${ }^{70}$ and Aboriginal families are less likely to have their own car. $^{71}$ Consequently, ACCHSs have often prioritised provision of transport. ${ }^{67}$

Having access to child and adolescent mental health specialists (particularly psychologists, paediatricians and some also suggested psychiatrists) was considered important. These findings are supported by data from the 'Bettering the Evaluation and Care of Health' study, which found that GPs predominantly refer to psychologists $(27 \%)$, and paediatricians $(28 \%)$ for paediatric mental health problems, in the general population. ${ }^{72}$ Participants felt that having these specialists available in-house at the ACCHS would achieve the best outcomes due to the cultural safety offered by the ACCHS, an assertion well supported in the literature. ${ }^{73} 74$

Several caveats should be noted regarding this study. First, while our findings appear to accord with the broader literature, they are based on the views of staff in only two urban ACCHSs and therefore may not be generalisable. Second, the views of consumers are not captured in the current paper, this will be an important focus of future work. Lastly, while our qualitative data are an important first step, it will be complemented by a detailed examination of the services available within and around each ACCHS and the way that pathways function between the services in practice.

\section{CONCLUSION}

This work is important as it summarises the perceptions of those working at the coalface providing healthcare to Aboriginal young people. It includes many Aboriginal staff members who are best placed to advise how to provide care to Aboriginal people. Participants reported that mental health problems made up a large proportion of their work with young people, and that more resources were needed to provide optimal care. Opportunities for improved care pathways were suggested at both an individual service provider and a systems level including, additional training in Aboriginal child and adolescent mental health, flexible guidelines, screening tools, more AHWs to work alongside GPs (with specific child and adolescent social and emotional well-being knowledge and remit) and access to child psychiatrists and psychologists, preferably located within the ACCHS. This paper provides new information on perceived current and ideal mental healthcare pathways and highlights practical opportunities for improvement.

\section{Author affiliations}

${ }^{1}$ The Sax Institute, Sydney, New South Wales, Australia

${ }^{2}$ Department of Medicine, McMaster University, Hamilton, Ontario, Canada

${ }^{3}$ Sydney School of Public Health, Poche Centre for Indigenous Health, Sydney, New South Wales, Australia

${ }^{4}$ Riverina Medical and Dental Aboriginal Corporation, Wagga Wagga, New South Wales, Australia
${ }^{5}$ College of Health and Medicine, Australian National University, Canberra, Australian Capital Territory, Australia

${ }^{6}$ Faculty of Medicine, Dentistry and Health Sciences, University of Melbourne, Melbourne, Victoria, Australia

${ }^{7}$ School of Public Health and Community Medicine, University of New South Wales, Sydney, New South Wales, Australia

Acknowledgements The authors would like to thank the Aboriginal Community Controlled Health Service staff who gave their time to participate in this study.

Contributors DK helped to design the study, collected data and contributed substantially to analysis and interpretation of the data and drafted the manuscript; $\mathrm{JN}, \mathrm{PF}$ and SS collected data and contributed substantially to analysis and interpretation of the data; MP analysed data and drafted the manuscript; JM contributed substantially to analysis and interpretation of the data; CDE and SJE contributed to interpretation of the data; AW conceived the study, contributed substantially to the design, analysis and interpretation of the study. All authors reviewed the manuscript critically for important intellectual content and gave final approval for it to be published.

Funding The Study of Environment on Aboriginal Resilience and Child Health (SEARCH) is funded through the Australian National Health and Medical Research Council (grant numbers APP358457, APP1035378, APP1023998), and an Australian Primary Health Care Research Institute Centre for Research Excellence Grant.

Competing interests None declared.

Patient consent for publication Not required.

Ethics approval Ethics clearance for this project has been provided by the Aboriginal Health and Medical Research Council of New South Wales (Approval no. 1110/15). This paper has been approved for publication by the Aboriginal Community Controlled Health Services involved in the study and by the Aboriginal Health and Medical Research Council of New South Wales.

Provenance and peer review Not commissioned; externally peer reviewed. Data sharing statement No data are available.

Open access This is an open access article distributed in accordance with the Creative Commons Attribution Non Commercial (CC BY-NC 4.0) license, which permits others to distribute, remix, adapt, build upon this work non-commercially, and license their derivative works on different terms, provided the original work is properly cited, appropriate credit is given, any changes made indicated, and the use is non-commercial. See: http://creativecommons.org/licenses/by-nc/4.0/.

\section{REFERENCES}

1. McGorry PD, Goldstone S. Is this normal? Assessing mental health in young people. Aust Fam Physician 2011;40:94-7.

2. Mission Australia. Youth mental health report: Youth Survey 20122016. 2017.

3. Australian Institute of Health and Welfare. Young Australians: their health and well-being 2007. Canberra, 2007.

4. Williamson A, D'Este C, Clapham K, et al. What are the factors associated with good mental health among Aboriginal children in urban New South Wales, Australia? Phase I findings from the Study of Environment on Aboriginal Resilience and Child Health (SEARCH). BMJ Open 2016;6:e011182.

5. Zubrick S, Silburn S, Lawrence D, et al. The Western Australian Aboriginal Child Health Survey: the social and emotional wellbeing of aboriginal children and young people. Perth: Telethon Institute for Child Health Research, 2005.

6. Centre for Epidemiology and Evidence. 2009-2010 Summary Report from the New South Wales Child Health Survey. Sydney, 2012.

7. Lawrence D, Johnson S, Hafekost J, et al. The mental health of children and adolescents. Report on the second Australian Child and Adolescent Survey of Mental Health and Wellbeing, 2015.

8. Goodman R. The strengths and difficulties questionnaire: a research note. J Child Psychol Psychiatry 1997;38:581-6.

9. Hawes DJ, Dadds MR. Australian data and psychometric properties of the strengths and difficulties questionnaire. Aust N Z J Psychiatry 2004;38:644-51.

10. Australian Bureau of Statistics. National Aboriginal and Torres Strait Islander Social Survey, 2002. Canberra: ABS, 2004.

11. Askew DA, Schluter PJ, Spurling GK, et al. Urban Aboriginal and Torres Strait Islander children's exposure to stressful events: a crosssectional study. Med J Aust 2013;199:42-5. 
12. Ziersch A, Gallaher G, Baum F, et al. Racism, social resources and mental health for Aboriginal people living in Adelaide. Aust $N Z \mathrm{~J}$ Public Health 2011;35:231-7.

13. Priest NC, Paradies YC, Gunthorpe W, et al. Racism as a determinant of social and emotional wellbeing for Aboriginal Australian youth. Med J Aust 2011;194:546-50.

14. Swan P, Raphael B. Ways forward: national aboriginal and torres straight islander mental health policy national consultancy report. Canberra: Commonwealth of Australia, 1995.

15. Leach LS, Butterworth P. The effect of early onset common mental disorders on educational attainment in Australia. Psychiatry Res 2012;199:51-7.

16. Cornaglia F, Crivallaro E, McNally S, et al. Mental Health and Educational Decisions. In: Centre for the Economics of Education. London: London School of Economics, 2012.

17. Indig D, Vecchiato C, Haysom L, et al. NSW Young People in Custody Health Survey: Full Report. Sydney: Justice Health and Juvenille Justice, 2009.

18. Kessler RC, Berglund P, Demler O, et al. Lifetime prevalence and age-of-onset distributions of DSM-IV disorders in the National Comorbidity Survey Replication. Arch Gen Psychiatry 2005;62:593.

19. Catania LS, Hetrick SE, Newman LK, et al. Prevention and early intervention for mental health problems in 0-25 year olds: Are there evidence-based models of care? Adv in Ment Health 2011;10:6-19.

20. Copeland WE, Adair CE, Smetanin P, et al. Diagnostic transitions from childhood to adolescence to early adulthood. J Child Psychol Psychiatry 2013;54:791-9.

21. Costello EJ, Foley DL, Angold A. 10-Year research update review: the epidemiology of child and adolescent psychiatric disorders: ii. developmental epidemiology. J Am Acad Child Adolesc Psychiatry 2006;45:8-25.

22. McGorry P, Purcell R, Hickie IB, et al. Investing in youth mental health is a best buy. Med $\mathrm{J}$ Aust 2007;187.

23. Burns BJ, Hoagwood K, Mrazek PJ. Effective treatment for mental disorders in children and adolescents. Clin Child Fam Psychol Rev 1999;2:199-254.

24. Patel V, Flisher AJ, Hetrick S, et al. Mental health of young people: a global public-health challenge. Lancet 2007;369:1302-13.

25. S-i I, Okajima I, Matsuoka H, et al. Cognitive Behavioural Therapy for Anxiety Disorders in Children and Adolescents: A Meta-Analysis. Child and Adolescent Mental Health 2007:12.

26. Faraone SV, Buitelaar J. Comparing the efficacy of stimulants for ADHD in children and adolescents using meta-analysis. Eur Child Adolesc Psychiatry 2010;19:353-64.

27. Williamson AB, Raphael B, Redman S, et al. Emerging themes in Aboriginal child and adolescent mental health: findings from a qualitative study in Sydney, New South Wales. Med J Aust 2010;192:603-5.

28. Kelly K, Dudgeon P, Gee G, et al. Living on the edge : social and emotional wellbeing and risk and protective factors for serious psychological distress among Aboriginal and Torres Strait Islander people: Cooperative Research Centre for Aboriginal Health, 2009.

29. Australian Health Ministers' Advisory Council. Aboriginal and Torres Strait Islander Health Performance Framework 2017 Report. Canberra, 2017.

30. Williamson A, Skinner A, Falster K, et al. Mental health-related emergency department presentations and hospital admissions in a cohort of urban Aboriginal children and adolescents in New South Wales, Australia: findings from SEARCH. BMJ Open 2018;8:e023544.

31. Australian Bureau of Statistics. Causes of death, Australia, 2015. Canberra: Australian Bureau of Statistics, 2016.

32. Antonio MC, Chung-Do JJ. Systematic review of interventions focusing on Indigenous adolescent mental health and substance use. Am Indian Alsk Native Ment Health Res 2015;22:36-46.

33. Azzopardi PS, Kennedy EC, Patton GC, et al. The quality of health research for young Indigenous Australians: systematic review. Med $\mathrm{J}$ Aust 2013;199:57-63.

34. Ralph S, Ryan K. Addressing the mental health gap in working with indigenous youth: some considerations for non-indigenous psychologists working with indigenous youth. Aust Psychol 2017;52:288-98.

35. Thomson O'Brien MA, Oxman AD, Haynes RB, et al. Local opinion leaders: effects on professional practice and health care outcomes. Cochrane Database Syst Rev 2000:2.

36. Panaretto KS, Wenitong M, Button S, et al. Aboriginal community controlled health services: leading the way in primary care. Med $\mathrm{J}$ Aust 2014;200:649-52.

37. National Mental Health Commission. National review of mental health programmes and services - fact sheet 9-What this means for General Practice and primary health care. Sydney, 2014
38. Goldberg D, Huxely P. Mental IIness in the community: the pathway to psychiatric care: Travistoick Publications. 1980.

39. Issakidis C, Andrews G. Who treats whom? An application of the pathways to care model in Australia. Aust N Z J Psychiatry 2006;40:74-86.

40. NSW Ministry of Health. Mental health clinical care and prevention model: a population mental health model: Mental Health Branch, 2001

41. Kilian A, Williamson A. What is known about pathways to mental health care for Australian Aboriginal young people?: a narrative review. Int J Equity Health 2018;17:12.

42. Wright $\mathrm{D}$, Gordon $\mathrm{R}$, Carr $\mathrm{D}$, et al. The study of environment on aboriginal resilience and child health (SEARCH): a long-term platform for closing the gap. Public Health Res Pract 2016;26:pii: 2631635.

43. Eades SJ, Taylor B, Bailey S, et al. SEARCH Investigators. The health of urban Aboriginal people: insufficient data to close the gap. Med $J$ Aust 2010;193:521-4.

44. National Aboriginal Community Controlled Health Organisation. Annual Report 2013-2014. Canberra, 2014.

45. Study of Environment on Aboriginal Resilience and Child Health Investigators. The Study of Environment on Aboriginal Resilience and Child Health (SEARCH): study protocol. BMC Public Health 2010;10:287.

46. Abbott P, Gordon E, Davison J. Expanding roles of Aboriginal health workers in the primary care setting: seeking recognition. Contemp Nurse 2008;27:157-64.

47. Given L. 100 Questions (and Answers) About Qualitative Research. Thousand Oaks: Sage, 2016.

48. Corbin J, Strauss A. Basics of qualitative research: techniques and procedures for developing grounded theory: Sage Publications, 2014.

49. Clarke V, Braun V. Using thematic analysis in psychology. Qual Res Psychol 2006;3.

50. Kessler RC, Barker PR, Colpe LJ, et al. Screening for serious mental illness in the general population. Arch Gen Psychiatry 2003;60:184-9.

51. Goldenring JM RD. Getting into adolescent heads: an essential update. Contemp Pediatr 2004;21.

52. Taylor K, Guerin P. Health care and Indigenous Australians: cultural safety in practice. Melbourne: Palgrave Macmillan, 2014.

53. Williamson $A$, McElduff $P$, Dadds $M$, et al. The construct validity of the strengths and difficulties questionnaire for aboriginal children living in Urban New South Wales, Australia. Aust Psychol 2014;49:163-70.

54. Zubrick S, Lawrence D, de Maio J, et al. Testing the reliability of a measure of Aboriginal children's mental health: an analysis based on the Western Australian Aboriginal Child Health Survey, report no.1351.0.55.011. 2006

55. Williamson A, Redman S, Dadds M, et al. Acceptability of an emotional and behavioural screening tool for children in Aboriginal Community Controlled Health Services in urban NSW. Aust N Z J Psychiatry 2010;44:894-900.

56. Kessler RC, Andrews G, Colpe LJ, et al. Short screening scales to monitor population prevalences and trends in non-specific psychological distress. Psychol Med 2002:32:959-76.

57. Thomas A, Cairney S, Gunthorpe W, et al. Strong Souls: development and validation of a culturally appropriate tool for assessment of social and emotional well-being in Indigenous youth. Aust N Z J Psychiatry 2010;44:40-8.

58. Westerman T. The development of the Westerman Aboriginal symptom checklist for youth: a measure to assess the moderating effects of cultural resilience with Aboriginal youth at risk of depression, anxiety and suicidal behaviours. Perth, WA: Curtin Univeristy, 2003.

59. NSW Health. Mental Health Outcomes \& Assessment Tools $(\mathrm{MH}$ OAT) Data Collection Reporting Requirement 1 July 2006: Health System Information \& Performance Reporting, editor, 2006.

60. Kilian A, Williamson A. What is known about best practices for mental health care delivery for Aboriginal young people: a narrative review. 2017.

61. Hinton R, Kavanagh DJ, Barclay L, et al. Developing a best practice pathway to support improvements in Indigenous Australians' mental health and well-being: a qualitative study. BMJ Open 2015;5:e007938.

62. The Royal Australasian College of Physicians. The role of paediatricians in mental health care of children and young people. 2016.

63. Cheung AH, Zuckerbrot RA, Jensen PS, et al. Guidelines for adolescent depression in primary care (GLAD-PC): Part II. Treatment and ongoing management. Pediatrics 2018;141:e20174082.

64. Zuckerbrot RA, Cheung A, Jensen PS, et al. Guidelines for adolescent depression in primary care (GLAD-PC): Part I. Practice 
preparation, identification, assessment, and initial management. Pediatrics 2018;141:e20174081.

65. Roberts JH, Bernard PM. 'Can he have the test for bipolar, doctor? His dad's got it': exploring the potential of general practitioners to work with children and young people presenting in primary care with common mental health problems - a clinical initiative. Ment Health Fam Med 2012;9:115-23.

66. Eley D, Hunter K, Young L, et al. Tools and methodologies for investigating the mental health needs of Indigenous patients: it's about communication. Australas Psychiatry 2006;14:33-7.

67. AH\&MRC. Aboriginal Communities Improving Aboriginal Health: An evidence review on the contribution of Aboriginal Community Controlled Health Services to improving Aboriginal health Sydney. 2015.

68. Dudgeon P, Milroy H, Walker R. Aboriginal and Torres Strait Islander Social and Emotional Wellbeing Australian Government Department of Health and Ageing. 2010.

69. Australian Government. National Aboriginal and Torres Strait Islander Health Plan 2013-2023: Department of Health, 2013.
70. Council of Social Service of New South Wales. Provided there's transport: transport as a barrier to accessing health care in NSW. Surry Hills, NSW: Council of Social Service of New South Wales, 2012.

71. Australian Government. Aboriginal and Torres Strait Islander Health performance framework 2014 report. 2014 https://www. pmc.gov.au/sites/default/files/publications/indigenous/HealthPerformance-Framework-2014/tier-2-determinants-health/213transport.html.

72. Charles J, Harrison CM, Britt H. Management of children's psychological problems in general practice 1970-1971, 1990-1991 and 2008-2009. Aust NZJ Psych 2011;45.

73. Lau P, Pyett P, Burchill M, et al. Factors influencing access to urban general practices and primary health care by Aboriginal Australians - a qualitative study. AlterNative: An International Journal of Indigenous Peoples 2012;8:66-84.

74. Durey A, Thompson SC. Reducing the health disparities of Indigenous Australians: time to change focus. BMC Health Serv Res 2012;12:151. 